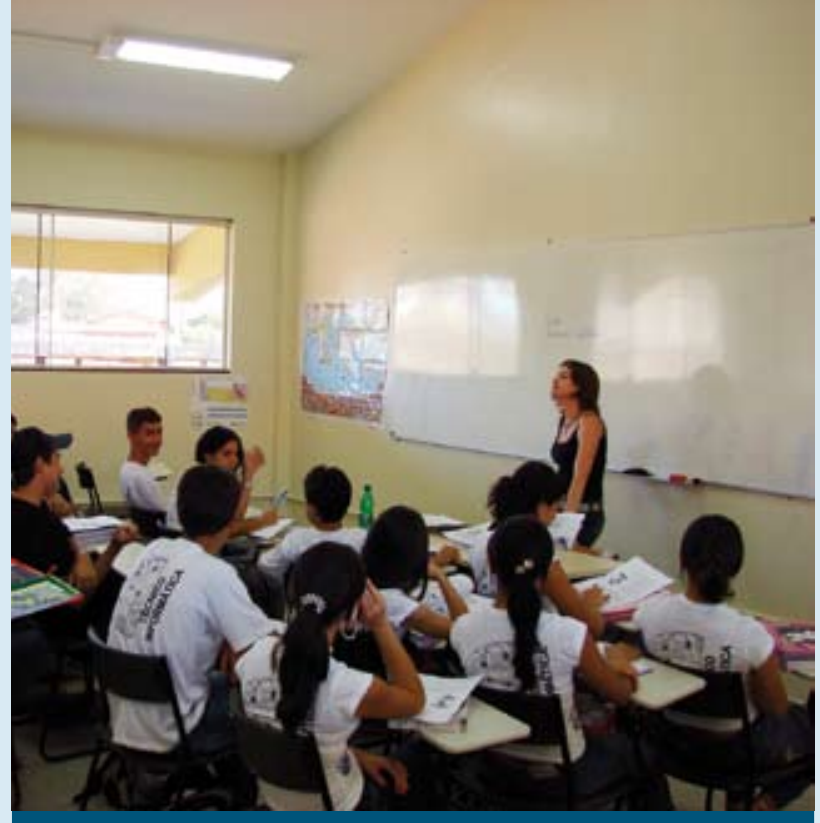

\title{
Diferenciais
} inovadores na formação de professores

\section{para a educação profissional}

LUCÍLIA REGINA DE SOUZA MACHADO

PALAVRAS-CHAVE:

Formação de professores; Licenciatura; Educação Profissional e Tecnológica.

\section{KEY WORDS:}

Formation of teachers; Licensorship; Professional and Technological Education. 


\section{Resumo}

Sem esgotar a riqueza das contribuições das intervenções dos participantes do GT - Formação de Professores para a Educação Profissional e Tecnológica, constituído pela Secretaria de Educação Profissional e Tecnológica - Setec do Ministério da Educação - MEC, por intermédio do Departamento de Políticas e Articulações Institucionais, este artigo reúne alguns aspectos da discussão ocorrida nas duas reuniões que este grupo realizou no segundo semestre de 2007. Trata-se de um assunto urgente, complexo e de enorme relevância educacional. O objetivo deste artigo é o de registrar considerações, indicações e recomendações feitas por este GT e sua finalidade é a de contribuir para a ampliação do debate de todos os setores interessados na construção de uma sólida e articulada política nacional de formação de professores para a educação profissional e tecnológica.

\section{Abstract}

This article puts together some aspects of debates that took place throughout two meetings that this group held in the second semester of 2007, without outrunning the richness of the participants' interventions' contributions of the GT - Teachers' Formation for the Professional and Technological Education, comprised of the Department of Professional and Technological Education - Setec do Ministério da Educação - MEC, in association with the Department of Institutional Articulations and Policies. This article has the goal of registering considerations, indications and recommendations made by this very GT and it also bears the aim to contribute for the debate's growth of all interested sectors in the construction of a solid and articulate national policy of the formation of teachers regarding the technological and professional education. 


\section{Introdução}

O estabelecimento de diretrizes e metas para a formação e valorização do magistério e demais profissionais da educação, no prazo de dez anos, é um dos objetivos do Plano Nacional de Educação, Lei no 10.172, de 9 de janeiro de 2001. Estamos em 2008, já se passaram sete anos! O item 7 deste Plano, que trata da Educação Tecnológica e Formação Profissional, aborda objetivos e metas (7.3), das quais é importante destacar duas, as metas 7 e 8 . A sétima solicita: "Modificar, dentro de um ano, as normas atuais que regulamentam a formação de pessoal docente para essa modalidade de ensino, de forma a aproveitar e valorizar a experiência profissional dos formadores". A não ser por esta última especificação, não deixa clara a extensão dessas modificações. A oitava meta, contudo, indica que esta modificação não seria muito significativa, já que reitera a norma atual de formar professores para a educação profissional e tecnológica por meio de programas especiais: "Estabelecer, com a colaboração entre o Ministério da Educação, o Ministério do Trabalho, as universidades, os Cefets, as escolas técnicas de nível superior, os serviços nacionais de aprendizagem e a iniciativa privada, programas de formação de formadores para a educação tecnológica e formação profissional" (grifos nossos).

No entanto, a Secretaria de Educação Profissional e Tecnológica do Ministério da Educação vem, há alguns anos, promovendo estudos e discussões sobre uma política mais ampla de formação de docentes para esta área da educação, que contemple a oferta de formação inicial, as licenciaturas. Como forma de ampliar a participação neste debate de todos os setores interessados e traçar delineamentos que expressem, de forma convergente, as necessidades e demandas neste campo, a Setec/MEC, por intermédio do Departamento de Políticas e Articulações Institucionais, constituiu um grupo de trabalho (GT) para sistematizar as questões referentes ao diagnóstico e às propostas de alternativas. A formação deste GT (Formação de Professores para a Educação Pro- fissional e Tecnológica) expressa o compromisso assumido pela Setec quando da realização do evento "Simpósio Educação Superior em Debate: Formação de Professores para a Educação Profissional e Tecnológica", realizado em setembro de 2006 por esta Secretaria e pelo Inep.

O GT Formação de Professores para a Educação Profissional e Tecnológica reuniu-se duas vezes no segundo semestre de 2007, uma na própria Setec (Brasília) e outra em São Luís (MA), nas dependências do Cefet/MA. Participaram destas discussões: Aléssio Trindade de Barros (Setec/MEC); Beatriz Helena Siqueira Katrein (Cefet/Pelotas); Caetana Juracy Rezende Silva (Setec/MEC); Edvaldo Pereira da Silva (Concefet e Cefet/Roraima); Francisco Aparecido Cordão (Senac/São Paulo); Lizete Kagami (Setec/MEC); Lucília Augusta Lindo de Paula (Anfope); Lucília Regina de Souza Machado (Centro Universitário UNA); Luiz Augusto Caldas Pereira (Setec) MEC); Maria Cristina Madeira da Silva (Sinasefe); Maria Rita Neto Sales Oliveira (Cefet/ Minas Gerais); Marisa Piedade Ramos (Cefet/Maranhão); Rita de Cássia Daher Botelho (Cefet/Campos); Roland Baschta Júnior (UTFPR).

Sem contemplar, naturalmente, toda a complexidade e riqueza de detalhes do conteúdo das intervenções dos participantes deste GT, o presente texto busca apresentar aspectos considerados fundamentais das considerações, indicações e recomendações que foram feitas nestas duas reuniões.

Com a chamada da Setec para a primeira reunião do ciclo de palestras para discussão das licenciaturas nos Institutos Federais de Educação, realizada, em Brasília, em março de 2008, a expectativa é que novos elementos se incorporarão a esta discussão.

O GT Formação de Professores para a Educação Profissional e Tecnológica deverá, assim, ao recuperar a discussão acumulada sobre o tema, concluir o desenho da proposta-base de licenciaturas para a Educação Profissional e Tecnológica, como contribuição ao interesse da Setec/MEC de apresentar ao Conselho Nacional de Educação o resultado dos seus estudos e conclusões. 


\section{Pequeno histórico da formação de professores para a educação profissional}

A falta de concepções teóricas consistentes e de políticas públicas amplas e contínuas tem caracterizado, historicamente, as iniciativas de formação de docentes especificamente para a educação profissional, no Brasil.

A criação da Escola Normal de Artes e Ofícios Wenceslau Brás, em 1917, no antigo Distrito Federal, constitui o início dessas iniciativas, já impregnado pelas dificuldades que vieram a seguir. Fechada pouco tempo depois, em 1937, essa escola, embora tenha chegado a ter 5.301 matriculados durante este período, habilitou apenas 381 professores (309 mulheres), em sua grande maioria para atividades de trabalhos manuais em escolas primárias. Em menor número, professores, mestres e contramestres para escolas profissionais.

Em 1942, a demanda por este tipo de formação foi acatada pela Lei Orgânica do Ensino Industrial (Art. 53), sem conseqüências práticas importantes. Destacase, no período, o primeiro Curso de Aperfeiçoamento de Professores do Ensino Industrial, em 1947, no Rio de Janeiro, com duração de um ano e três meses, iniciativa da Comissão Brasileiro-Americana do Ensino Industrial - CBAI, uma inspiração da Usaid (Agência dos Estados Unidos para o Desenvolvimento Internacional). Esta comissão patrocinou ainda a formação de gestores, enviando, neste mesmo ano, dois grupos de dez diretores de escolas técnicas industriais para o curso de Administração de Escolas Técnicas do State College (Pensilvânia, EUA).

Com a LDB no 4.024/1961, artigo 59, dois caminhos separados foram estabelecidos para a formação de professores. Em faculdades de filosofia, ciências e letras, os que se destinassem ao magistério no ensino médio. Em cursos especiais de educação técnica, os que se habilitassem para disciplinas do ensino técnico. Este artigo, porém, demorou a ser regulamentado, o que aconteceu somente em 1967 e 1968.

Antes desta regulamentação, o MEC chegou a tomar algumas iniciativas. Em 1961, baixou a Portaria Ministerial 141/61, que estabeleceu normas para registros de professores do ensino industrial e o ConseIho Federal de Educação emitiu parecer (parecer CFE no 257/63) para aprovar o curso especial de educação técnica em cultura feminina, destinado a formar o magistério de economia doméstica e trabalhos manuais. O MEC definiu, também, pela Portaria Ministerial $174 / 65$, a carga horária (800 aulas) e o número mínimo de dias letivos (180) do curso de didática do ensino agrícola. Houve ainda, em 1965, a criação da Universidade do Trabalho de Minas Gerais (Utramig), que, nos seus objetivos, incluía a formação de instrutores e professores de disciplinas específicas do ensino técnico industrial.

O Parecer CFE no 12/1967 foi o primeiro dispositivo de regulamentação dos cursos especiais de educação técnica previstos pela LDB no 4.024/61 e teve basicamente o objetivo de esclarecer a finalidade destes cursos. Com base neste Parecer, a Portaria Ministerial no 111/68 esclareceu que tais cursos seriam destinados aos diplomados em nível superior ou em nível técnico em cujos currículos figurassem disciplinas escolhidas para lecionar e definiu o mínimo de 720 horas-aula. Cursos reservados a formar instrutores teriam, pelo menos, 200 horas-aula. O Art. 59 foi também regulamentado pelo Parecer CFE no 479/68, que estabeleceu a obrigatoriedade de seguir currículo mínimo e as orientações do Parecer no 262/62, que fixava a duração da formação dos professores do ensino médio geral, incluindo as posteriores disposições que viessem modificar, esclarecer ou substituir tal dispositivo.

A reforma universitária (Lei no 5.540/68) fez uma exigência que foi, porém, logo em seguida relaxada: determinou que a formação de todos os professores do ensino de segundo grau, tanto para disciplinas gerais quanto técnicas, deveria se dar em nível superior. Normas complementares (Art. 16 do Decreto-lei no 464/69) argüiram, contudo, que não havendo professores e especialistas formados em nível superior, exames de suficiência realizados em instituições oficiais de ensino superior indicadas pelo CFE poderiam conferir esta habilitação. Tal Decreto-lei estabelecia, contudo, um prazo de cinco anos para a regularização da situação dos não diplomados em nível superior que, na data da publicação da Lei № 5.540/68, ministravam disciplinas específicas no ensino técnico ou exerciam funções de administração e de especialistas no ensino primário, exigência que não foi, entretanto, atendida.

A carência de professores de ensino técnico habilitados em nível superior, exigência da Lei no 5.540/68, 
levou o MEC a ser autorizado, em 1969, por meio do Decreto-lei 655/69, a organizar e coordenar cursos superiores de formação de professores para o ensino técnico agrícola, comercial e industrial. Criou-se ${ }^{1}$ uma agência executiva do Departamento de Ensino Médio do MEC (Fundação Cenafor ou Centro Nacional de Aperfeiçoamento de Pessoal para a Formação Profissional) $)^{2}$ e o CFE emitiu pareceres de orientação ${ }^{3}$.

Foram, então, desenhados cursos emergenciais, denominados Esquema I e Esquema II (Portaria Ministerial 339/70). Os primeiros para complementação pedagógica de portadores de diploma de nível superior. Os segundos para técnicos diplomados e incluíam disciplinas pedagógicas do Esquema I e as de conteúdo técnico específico.

Nesta época, chegou-se a planejar a formação de professores para a formação profissional. Em 1970, o CFE aprovou um plano nesse sentido e outro adicional sobre concurso vestibular e currículos, por meio dos Pareceres 151/70 e 409/70, respectivamente. Em 1971, surgiu outro plano (Parecer 111/71) sobre formação de professores para disciplinas especializadas, mas voltado para o ensino médio em geral para atender à Lei no 5.692/714 . As diretorias do MEC de ensino agrícola, industrial e comercial foram fundidas em um só departamento de ensino médio. Face à urgência de atender ao que prescre- via esta lei, os cursos Esquemas I e II ganharam normas adicionais do $\mathrm{MEC}^{5}$ e o CFE tratou de currículo mínimo para a formação de professores para disciplinas correspondentes às áreas econômicas primária, secundária e terciária (Parecer 1.073/72).

O CFE, nesta época, recebeu um grande número de consultas, pois, àquela época, havia a exigência de obter registros junto ao MEC para o exercício da profissão docente, baixando normas para os professores das disciplinas específicas do ensino de $2^{\mathrm{O}}$ grau $^{6}$, sobre possibilidades de continuação de estudos e ingressos nos cursos Esquema I e II . Os assuntos referentes a registro de professor e fixação de currículo mínimo ainda foram objeto de atenção do CFE até o ano de $1976^{8}$.

Em 1977, a Resolução no 3 do CFE instituiu a licenciatura plena para a parte de formação especial do $2^{o}$ grau, fixando currículo mínimo e determinando que as instituições de ensino que ofertassem os Esquemas I e II os transformassem em licenciaturas. Foi dado um prazo máximo de três anos para isso, a partir da vigência dessa norma. Excepcionalmente, o Esquema I foi admitido e apenas para as regiões com falta de recursos materiais e humanos para implantar esta licenciatura. Passados 30 anos, não se generalizou a licenciatura e pouco sucesso se obteve com relação à implantação dessa licenciatura.

1. Decreto-lei no 616/69.

2. O Cenafor supervisionava os planos de execução de cursos dos centros de educação técnica (Centro de Educação Técnica do Rio Grande do Sul - Cetergs; Centro de Educação Técnica da Guanabara - Ceteg; Centro de Ensino Técnico de Brasília - Ceteb; Centro de Educação Técnica da Bahia - Ceteba; Centro de Educação Técnica do Nordeste - Cetene; Centro de Educação Técnica da Amazônia - Ceteam).

3. Parecer CFE no 266/69, para as áreas comercial e industrial; Parecer CFE no 392/69, para o Ensino Médio Técnico; Parecer CFE no 638/69, sobre a equivalência dos cursos de Formação de Professores do Ensino Industrial e Técnico; Parecer CFE no 214/70, para a formação de professores do ensino técnico-industrial. O Parecer CFE no 74/70 veio para estabelecer cargas horárias desses cursos especiais. No mínimo, 1.600 horas-aula cumpridas em 9 meses ou 800 horas-aula, em 5 meses, se o candidato já tivesse formação técnica específica em nível médio ou superior.

4. Que reformou o ensino de $1 \underline{\text { o e }} 2^{\underline{o}}$ graus e instituiu a profissionalização universal e compulsória neste último. O Relatório do Grupo de Trabalho (1970), que serviu de base para o anteprojeto desta lei, indicou a necessidade de formar cerca de 200.000 professores até 1980.

5. Portaria Ministerial no 432/71.

6. Parecer CFE no 3.761/74 (área econômica primária); Parecer CFE no 3.771/74 (docente de disciplinas específicas do antigo ensino médio técnico); Parecer CFE no 3.774/74 (disciplinas específicas do ensino de 2º grau); Parecer CFE no 3.775/74 (nível do antigo curso de formação e aperfeiçoamento de professores do ensino comercial).

7. Parecer CFE no $1.886 / 75$, sobre a possibilidade de continuação de estudos para professores de artes práticas, habilitação em artes industriais, e ingresso no curso de formação de professores de matérias específicas - Esquema II - para o exercício do magistério de 2 o grau. Parecer CFE no 1.902/75 sobre ingresso de diplomados em nível superior em cursos de Esquema I. Parecer CFE no $2.517 / 75$ sobre possibilidade de complementação dos estudos de licenciatura plena dentro do Esquema II para os licenciados em cursos de curta duração. Parecer CFE no 51/76 sobre a extensão a qualquer diplomado em nível superior da complementação pedagógica prevista para os cursos do Esquema I pela Portaria 432/71.

8. Parecer CFE no 532/76 sobre registro de professor de disciplinas especializadas do ensino de 2o grau e Parecer no $4.417 / 76$ sobre currículo mínimo do curso de graduação de professores da parte de formação especial do currículo do ensino de 2 o grau. 
A transformação das Escolas Técnicas Federais de Minas Gerais, Paraná e Rio de Janeiro em Cefets (os primei-

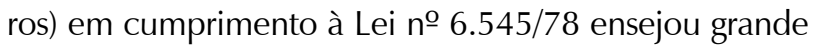
expectativa nesse sentido, pois um de seus objetivos era precisamente oferecer ensino superior de licenciatura plena e curta, visando à formação de professores e especialistas para as disciplinas especializadas do ensino de $2^{\mathrm{o}}$ grau e dos cursos de formação de tecnólogos.

Entre 1979 e 1982, o CFE emitiu diversos pareceres: sobre registro de professores oriundos dos Esquemas I e ${ }{ }^{9}$, sobre autorização para a oferta de cursos emergenciais (Parecer CFE 1.004/80), sobre a adaptação desses cursos aos termos da Resolução CFE no 3/77 (licenciaturas) ${ }^{10}$, incluindo resolução sobre o assunto (Resolução CFE no. 1/81). Mas, em vez das licenciaturas, os esquemas se impunham, chegando a Sesu/MEC a aprovar, em 1979, um plano para cursos emergenciais (Parecer Sesu/ MEC no. 47/79).

Houve, assim, um relaxamento da Resolução CFE no 3/77, assim como o ocorrido com a exigência da Lei no 5.540/68, confirmado com a publicação da Resolução CFE no $7 / 82$, que alterou os artigos $1^{0}$ e e 9 ㅇ da Resolução CFE no 3 e tornou opcional a formação de professores da parte de formação especial do currículo de ensino de $2^{\circ}$ grau, por via dos Esquemas I e II ou por via da licenciatura plena. Normas sobre a organização e o funcionamento de todas essas modalidades de cursos foram definidas na Portaria MEC no 299/82.

A Resolução CFE no 7/82 (de flexibilização) surgiu no mesmo ano em que se promulgou a Lei no 7.044/82, que alterou dispositivos da Lei no 5.692/71, referentes à obrigatoriedade da profissionalização do aluno no ensino de $2^{\mathrm{o}}$ grau. A nova lei manteve o objetivo geral do ensino de 10 e $2 \underline{o}$ graus de proporcionar ao educando a formação necessária ao desenvolvimento de suas potencialidades como elemento de auto-realização e para o exercício consciente da cidadania, mas aboliu a exigência da qualificação para o trabalho no $2^{\circ}$ grau.
Ambos os níveis de ensino deveriam, doravante, fazer simplesmente uma preparação geral para o trabalho, entendida como um elemento obrigatório de formação integral do aluno. No $2^{\circ}$ grau, a habilitação profissional ficou como opcional e a critério do estabelecimento de ensino, que deveria, então, atender aos mínimos fixados pelo CFE para conteúdos e duração.

Pouco tempo depois, em 1986, houve a extinção dos órgãos dedicados à formação docente para o ensino técnico vinculados ao MEC: a Coordenação Nacional do Ensino Agrícola - Coagri e o Centro Nacional de Aperfeiçoamento de Pessoal para a Formação Profissional - Cenafor ${ }^{11}$. Suas responsabilidades foram transferidas para a Secretaria de Ensino de Segundo Grau (SESG) do MEC, que instituiu um grupo de trabalho, por meio da Portaria Sesu/Sesg/MEC no 355/87, destinado a elaborar proposta de cursos regulares de licenciatura plena em matérias específicas do ensino técnico industrial de 2o grau. Esta proposta foi encaminhada em 1989 ao CFE. A formação de docentes para as disciplinas específicas do $2^{\circ}$ grau permaneceu em pauta, sendo objeto, em 1989, do Parecer no 632/89, da Comissão Especial Interconselhos (CFE e Conselho de Mão-de-Obra). Em 1991, o CFE, mediante Parecer no 31/91, sugere o reexame da legislação pertinente, maior flexibilidade e melhor compatibilidade entre os textos legais que tratam do assunto. A discussão mais geral sobre a nova LDB ocupou, porém, os debates educacionais.

A LDB no 9.394/96 trouxe referências gerais para a formação de professores, extensivas aos de disciplinas específicas: formação mediante relação teoria e prática, aproveitamento de estudos e experiências anteriores dos alunos desenvolvidas em instituições de ensino e em outros contextos, e prática de ensino de, no mínimo, 300 horas. O Decreto no 2.208/97, que veio regulamentar os artigos da nova LDB referentes à educação profissional, interpretou, no seu artigo 9o 9 , que as disciplinas do ensino técnico poderiam ser ministradas não apenas por professores, mas por instrutores e monitores, uma incúria com

9. Parecer CFE no 919/79; Parecer CFE no 136/80; Parecer CFE no 867/80; Parecer CFE no 589/80; Parecer CFE no 67/81 e Parecer CFE no 335/82.

10. Parecer CFE no 1.092/80.

11. Pela Portaria Ministerial no 821/86, foram transferidas as responsabilidades da extinta Coagri para a Sesg/MEC, e pela Portaria MEC no 66/87, as responsabilidades do Cenafor também para a Sesg/MEC. 
relação às exigências de habilitação docente. Previa que estes deveriam ser selecionados, principalmente, pela experiência profissional, que a preparação para o magistério não precisaria ser prévia, pois poderia se dar em serviço e manteve a admissão de programas especiais de formação pedagógica. Apesar disso, cursos regulares de licenciatura foram também citados, mas sem quaisquer outras referências mais concretas.

O CNE, mediante Resolução no 2/97, dispôs sobre os programas especiais de formação pedagógica de docentes para as disciplinas do currículo do ensino fundamental e do ensino médio e, relanceando os olhos para a educação profissional em nível médio, achou uma forma de incluir a formação de professores para esta modalidade nesta resolução, sem promover a discussão sobre a alternativa das licenciaturas. Destinados aos diplomados em cursos superiores, tais cursos especiais devem se relacionar à habilitação pretendida, enfatizar a metodologia de ensino específica a ela, concedendo direitos a certificado e registro profissional equivalentes à licenciatura plena; tudo isso em pelo menos 540 horas, incluindo a parte teórica e prática, esta com duração mínima de 300 horas. Ou seja, a parte teórica se reduziu ao mínimo de 240 horas, podendo ser, ainda, oferecida na modalidade a distância. A Resolução CNE no 2/97 previa avaliação desta política pelo CNE num prazo de cinco anos. Diversos pareceres foram emitidos por esse órgão para responder às consultas recebidas sobre essa norma, incluindo uma originada do Poder Judiciário ${ }^{12}$.

Em 4/4/2006, foi aprovado pelo CNE o Parecer CNE/ CP no 5/06, que aprecia a Indicação CNE/CP no 2/02 sobre diretrizes curriculares nacionais para cursos de formação de professores para a educação básica. Este parecer prevê que "os cursos de licenciatura destinados à formação de professores para os anos finais do ensino fundamental, o ensino médio e a educação profissional de nível médio serão organizados em habilitações especializadas por componente curricular ou abrangentes por campo de conhecimento, conforme indicado nas diretrizes curriculares pertinentes".

\section{Licenciaturas para a educação profissional: uma necessidade urgente}

A carência de pessoal docente qualificado tem se constituído num dos pontos nevrálgicos mais importantes que estrangulam a expansão da educação profissional no país. Atualmente, anunciam-se diversas medidas orientadas à expansão quantitativa da oferta desta modalidade educativa no país, incluindo-se a reorganização das instituições federais de educação profissional e tecnológica. Por outro lado, ampliou-se o entendimento de que essa modalidade educacional contempla processos educativos e investigativos de geração e adaptação de soluções técnicas e tecnológicas de fundamental importância para o desenvolvimento nacional e o atendimento de demandas sociais e regionais, o que requer o provimento de quadros de formadores com padrões de qualificação adequados à atual complexidade do mundo do trabalho.

Compreende-se que a resolução deste gargalo é condição fundamental à organização, planejamento e coordenação nacional dos esforços de superação da estrutura fragmentada que ainda caracteriza a educação profissional no Brasil, requisito fundamental à sua institucionalidade, e que isso só será possível mediante o desenvolvimento de concepção consistente e política nacional ampla e contínua de formação profissional de docentes para esta área.

Há, hoje, ofertas formativas diversificadas de formação de docentes para este campo, mas são muito reduzidas considerando o potencial de demanda e nem sempre atendem a todos os perfis de entrada dos candidatos. Essas ofertas são constituídas por programas especiais, cursos de pós-graduação, formação em serviço e formação a distância. Poucas são, entretanto, as iniciativas de cursos de licenciatura. no 678/01, Parecer CNE/CP no 25/01, referente à consulta do Poder Judiciário, Parecer CNE/CP no 25/02 e Parecer CNE/CEB no 37/02. 


\section{Uma política definida para a formação de professores que atenda \\ a tais necessidades será certamente um grande estímulo para a superação da atual debilidade teórica e prática deste campo educacional com relação aos aspectos pedagógicos e didáticos.}

Apesar disso, as licenciaturas têm sido apontadas como absolutamente essenciais por serem o espaço privilegiado da formação docente inicial e pelo importante papel que podem ter na profissionalização docente, para o desenvolvimento de pedagogias apropriadas às especificidades da educação profissional, o intercâmbio de experiências no campo da educação profissional, o desenvolvimento da reflexão pedagógica sobre a prática docente nesta área, o fortalecimento do elo entre ensino-pesquisa-extensão, pensar a profissão, as relações de trabalho e de poder nas instituições escolares, a responsabilidade dos professores etc.

As exigências com relação ao perfil dos docentes da educação profissional estão, hoje, mais elevadas. Não é mais suficiente o padrão do artesanato, quando o mestre da oficina-escola se apresentava como o espelho que o aluno praticante deveria adotar como referência. Superado também está o padrão da escolaoficina, que impunha ao aluno a aplicação de séries metódicas de aprendizagem. Instrutores recrutados nas empresas, segundo o padrão de que para ensinar basta saber fazer, apresentam grandes limitações não somente pedagógicas, mas também teóricas com relação às atividades práticas que ensinam.

Os professores da educação profissional enfrentam novos desafios relacionados às mudanças organizacionais que afetam as relações profissionais, aos efeitos das inovações tecnológicas sobre as atividades de trabalho e culturas profissionais, ao novo papel que os sistemas simbólicos desempenham na estruturação do mundo do trabalho, ao aumento das exigências de qualidade na produção e nos serviços, à exigência de maior atenção à justiça social, às questões éticas e de sustentabilidade ambiental. São novas demandas à construção e reestruturação dos saberes e conhecimentos fundamentais à análise, reflexão e intervenções críticas e criativas na atividade de trabalho.
Superar o histórico de fragmentação, improviso e insuficiência de formação pedagógica que caracteriza a prática de muitos docentes da educação profissional de hoje implica reconhecer que a docência é muito mais que mera transmissão de conhecimentos empíricos ou processo de ensino de conteúdos fragmentados e esvaziados teoricamente. Para formar a força de trabalho requerida pela dinâmica tecnológica que se dissemina mundialmente, é preciso um outro perfil de docente capaz de desenvolver pedagogias do trabalho independente e criativo, construir a autonomia progressiva dos alunos e participar de projetos interdisciplinares.

Uma política definida para a formação de professores que atenda a tais necessidades será certamente um grande estímulo para a superação da atual debilidade teórica e prática deste campo educacional com relação aos aspectos pedagógicos e didáticos.

Entidades da área da educação, tais como Anped, Anfoppe, Anpae, Cedes e Forundir, têm reiterado argumentos que evidenciam a impropriedade das soluções que acabam transformando políticas emergenciais de formação de professores em soluções permanentes. Têm, igualmente, chamado a atenção para a necessidade de uma ampla e massiva política que leve à consolidação de um sistema nacional de formação docente, que inclua a modalidade inicial, a continuada, as necessárias articulações entre formação inicial e continuada, bem como estratégias de formação de formadores. O que se requer é a inclusão das demandas de formação de professores para a educação profissional no bojo desta discussão, preservando-se o caráter unitário deste sistema nacional de formação docente, evitando-se dar continuidade à fragmentação das políticas.

Isso porque professores de educação básica e de educação profissional comungam das mesmas neces- 
sidades com relação à valorização de sua formação, desenvolvimento profissional, condições de trabalho, salário e carreira, que os permitam enfrentar a precarização e se envolverem com todo o comprometimento necessário à educação de qualidade. Por outro lado, é cada vez maior a aproximação entre esses dois grupos de profissionais docentes, em razão da expansão da educação profissional de nível técnico integrada ao ensino médio, inclusive na modalidade EJA.

As entidades acima referidas têm chamado a atenção, também, para a necessidade de que a formação inicial do jovem egresso do ensino médio seja desenvolvida de forma presencial nas licenciaturas e não em cursos na modalidade a distância. Salientam, por fim, a importância da política de acompanhamento dos processos de criação, credenciamento e autorização de cursos e de avaliação permanente dos mesmos.

\section{Especificidades da formação de professores para a educação profissional}

A educação profissional tem no seu objeto de estudo e intervenção sua primeira especificidade, a tecnologia. Esta, por sua vez, se configura como uma ciência transdisciplinar das atividades humanas de produção, do uso dos objetos técnicos e dos fatos tecnológicos. Do ponto de vista escolar, é disciplina que estuda o trabalho humano e suas relações com os processos técnicos.

É próprio do ensinar-aprender tecnologia e, portanto, da docência na educação profissional tratar da intervenção humana na reorganização do mundo físico e social e das contradições inerentes a esses processos, exigindo discutir questões relacionadas às necessidades sociais e às alternativas tecnológicas.
Porém, o caráter operatório da tecnologia e a possibilidade de transformar o real, mudança que constitui um efeito concreto fundamental, podem ganhar representações diversas que acompanham os sentidos atribuíveis à idéia de eficácia e de sucesso. Daí a necessidade de uma formação consistente, fundamentada e crítica.

Por outro lado, os conhecimentos tecnológicos, ao se condensarem em atos humanos e em artefatos (conhecimentos mortos), são historicamente determinados e nem sempre são transmissíveis pelos meios discursivos, exigindo do docente e do aluno um esforço de pesquisa, de decodificação e re-significação.

A docência na educação profissional, portanto, não se faz sem a avaliação de opções tecnológicas, o que requer apreender conhecimentos tácitos e o estadoda-arte do desenvolvimento tecnológico, entender os motivos pelos quais há problemas em aberto mesmo existindo soluções tecnológicas para os mesmos, aprender com lições deixadas por experiências pessoais ou coletivas passadas e imaginar futuros possíveis ou alternativos das tecnologias.

Há invenções tecnológicas que precedem ao desenvolvimento das ciências indicando a necessidade de abordagens não lineares das relações entre ciência e tecnologia que levem em conta as peculiaridades destes campos.

É importante ter em vista que a mudança tecnológica também é obra dos usuários de tecnologia, que a transformam e a adaptam quando tomam decisões visando aumentar a confiabilidade e a rentabilidade destes recursos ou diminuir os riscos implicados (por exemplo, sobre meio ambiente), levando à produção de novos saberes nascidos destas iniciativas e experiências práticas. Daí porque há necessidade de dar atenção também ao "diálogo" entre os conhecimentos tecnológicos escolarizados e os que nascem dessas iniciativas e experiências práticas extra-escolares. 


\section{É pressuposto básico que o docente da educação profissional seja, essencialmente, um sujeito da reflexão e da pesquisa, aberto ao trabalho coletivo e à ação crítica e cooperativa, comprometido com sua atualização permanente na área de formação específica e pedagógica.}

As formas de organização da educação profissional também são muito heterogêneas, implicando uma diversidade de currículos, status dos formadores e das instituições de formação: divisão em setores econômicos (agrícola, industrial e serviços), em áreas profissionais ou em eixos tecnológicos, variada rede de escolas e centros, mantenedoras públicas nas três esferas governamentais, mantenedoras privadas, regionalização, níveis, relação com outras modalidades educacionais etc.

No Brasil, inclui-se na educação profissional: os programas de formação inicial e continuada de trabaIhadores; o ensino técnico nas formas concomitante, subseqüente e integrado ao ensino médio; as variantes da formação inicial e continuada e do ensino técnico quando ministradas de forma articulada com a educação de jovens e adultos e a graduação tecnológica.

É preciso considerar, portanto, a complexidade deste todo e as necessidades de cada uma das particularidades internas ao conjunto da educação profissional brasileira. Apenas para ficar no nível do ensino técnico, é preciso lembrar que quando o docente atua:

a) no ensino técnico integrado ao médio, ele deve saber integrar os conhecimentos científicos, tecnológicos, sociais e humanísticos, que compõem o núcleo comum de conhecimentos gerais e universais, e os conhecimentos e habilidades relativas às atividades técnicas de trabalho e de produção relativas ao curso técnico em questão;

b) no ensino técnico concomitante ao médio, ele deve saber articular o planejamento e o desenvolvimento dos cursos, de modo a aproveitar oportunidades educacionais disponíveis; e

c) no ensino técnico subseqüente ao médio, ele deve saber lidar com um alunado heterogêneo que já concluiu o ensino médio e reforçar a formação obtida na educação básica paralelamente ao desenvolvimento dos conteúdos específicos à habilitação.
Dada esta diversidade de situações e dispersão das soluções que vêm sendo praticadas, os professores da educação profissional são levados a atuar com um mínimo de orientações pedagógicas e técnicas. Com isso, o trabalho de transposição didática é realizado geralmente sem qualquer avaliação externa.

Por último, a especificidade da formação dos docentes da EPT também se constitui pela necessidade urgente de sua profissionalização e valorização.

\section{0 perfil de docente a ser formado para a educação profissional}

É pressuposto básico que o docente da educação profissional seja, essencialmente, um sujeito da reflexão e da pesquisa, aberto ao trabalho coletivo e à ação crítica e cooperativa, comprometido com sua atualização permanente na área de formação específica e pedagógica, que tem plena compreensão do mundo do trabalho e das redes de relações que envolvem as modalidades, níveis e instâncias educacionais, conhecimento da sua profissão, de suas técnicas, bases tecnológicas e valores do trabalho, bem como dos limites e possibilidades do trabalho docente que realiza e precisa realizar.

As bases tecnológicas constituem um diferencial importante do perfil do docente a ser formado, pois se referem ao conjunto sistematizado de conceitos, princípios e processos relativos a um eixo tecnológico e a determinada área produtiva - de bens e serviços, resultante, em geral, da aplicação de conhecimentos científicos. Nesse sentido, o perfil do docente precisa, também, estar alicerçado em bases científicas, nos conceitos e princípios das ciências da natureza, da matemática e das ciências humanas, presentes nas tecnologias e que fundamentam suas opções estéticas e éticas e seu campo de atuação. Precisa, ainda, estar apoiado 
em bases instrumentais relativas a linguagens e códigos, que permitem ler e interpretar a realidade e comunicar-se com ela, habilidades mentais, psicomotoras e de relacionamento humano.

Entende-se que se trata de um profissional que sabe o que, como e por que fazer e que aprendeu a ensinar, para desenvolver idônea e adequadamente outros profissionais. Desta forma, tem papel e compromisso como educador, independentemente de outra atividade que venha a ter, contribuindo, assim, como participante ativo, para o desenvolvimento da educação profissional.

Deve, portanto, ter capacidade para elaborar estratégias; estabelecer formas criativas de ensino-aprendizagem; prever as condições necessárias ao desenvolvimento da educação profissional, considerando suas peculiaridades, as circunstâncias particulares e as situações contextuais em que se desenvolve; realizar um trabalho mais integrado e interdisciplinar; promover transposições didáticas contextualizadas e vinculadas às atividades práticas e de pesquisa.

O perfil profissional do docente da educação profissional engloba, além das especificidades das atividades pedagógicas relativas ao processo de ensino-aprendizagem neste campo, as dimensões próprias do planejamento, organização, gestão e avaliação desta modalidade educacional nas suas íntimas relações com as esferas da educação básica e superior.

Portanto, o professor da educação profissional deve ser capaz de permitir que seus alunos compreendam, de forma reflexiva e crítica, os mundos do trabalho, dos objetos e dos sistemas tecnológicos dentro dos quais estes evoluem; as motivações e interferências das organizações sociais pelas quais e para as quais estes objetos e sistemas foram criados e existem; a evolução do mundo natural e social do ponto de vista das relações humanas com o progresso tecnológico; como os produtos e processos tecnológicos são concebidos, fabricados e como podem ser utilizados; métodos de trabalho dos ambientes tecnológicos e das organizações de trabalho. Precisa saber desenvolver comportamentos pró-ativos e socialmente responsáveis com relação à produção, distribuição e consumo da tecnologia.

O professor da educação profissional deve ser capaz de descrever práticas profissionais (como, por quem e dentro de que condições uma atividade é realizada),

\section{0 professor da educação}

profissional deve ser capaz

de permitir que seus alunos

compreendam, de forma

reflexiva e crítica, os mundos

do trabalho, dos objetos e dos

sistemas tecnológicos dentro

dos quais estes evoluem.

de levar em conta o uso que quer fazer desta descrição no processo de ensino-aprendizagem (tipo de apropriação e grau de utilização das técnicas) e de estabelecer a diferença entre ensinar práticas e ensinar os saberes sobre estas práticas (construção mais ou menos elaborada, mais ou menos formalizada destas práticas).

Portanto, é desejável que, além da experiência profissional articulada à área de formação específica, saiba trabalhar com as diversidades regionais, políticas e culturais existentes, educar de forma inclusiva, contextualizar o conhecimento tecnológico, explorar situações-problema, dialogar com diferentes campos de conhecimentos e inserir sua prática educativa no contexto social, em todos os seus níveis de abrangência.

Em síntese, o perfil do docente da educação profissional precisa dar conta de três níveis de complexidade: a) desenvolver capacidades de usar, nível mais elementar relacionado à aplicação dos conhecimentos e ao emprego de habilidades instrumentais; b) desenvolver capacidades de produzir, que requer o uso de conhecimentos e habilidades necessários à concepção e execução de objetivos para os quais as soluções tecnológicas existem e devem ser adaptadas; e c) desenvolver capacidades de inovar, nível mais elevado de complexidade relacionado às exigências do processo de geração de novos conhecimentos e novas soluções tecnológicas. 


\section{Propostas de cursos de licenciatura destinados à formação inicial de docentes para a educação profissional}

\begin{tabular}{|c|c|}
\hline \multicolumn{2}{|c|}{ I. Curso de licenciatura para graduados } \\
\hline Carga horária mínima global & 1.200 horas \\
\hline Estrutura curricular pedagógica & $\begin{array}{l}800 \text { horas de formação didático-pedagógica } \\
400 \text { horas de estágio pedagógico supervisionado }\end{array}$ \\
\hline Habilitados para docência em & $\begin{array}{l}\text { Cursos técnicos de nível médio } \\
\text { Cursos superiores de graduação tecnológica }\end{array}$ \\
\hline $\begin{array}{l}\text { Limites de ação do } \\
\text { profissional docente }\end{array}$ & $\begin{array}{l}\text { Docência apenas dos conteúdos profissionais, no âmbito das bases } \\
\text { tecnológicas do seu conhecimento }\end{array}$ \\
\hline Vantagens para os formandos & $\begin{array}{l}\text { Atuar em profissões regulamentadas, com responsabilidade técnica pela docência } \\
\text { Curso pode equivaler a um curso de especialização (LS) }\end{array}$ \\
\hline \multicolumn{2}{|c|}{ II. Curso de licenciatura integrado com o curso de graduação em tecnologia } \\
\hline Carga horária mínima global & Até 4.000 horas \\
\hline Estrutura curricular pedagógica & $\begin{array}{l}2.400 \text { horas ou } 2.000 \text { horas ou } \\
1.600 \text { horas de educação tecnológica } \\
800 \text { horas de formação didático-pedagógica } \\
400 \text { horas de estágio pedagógico supervisionado } \\
400 \text { horas de estágio profissional específico }\end{array}$ \\
\hline Habilitados para docência em & Cursos técnicos de nível médio \\
\hline $\begin{array}{l}\text { Limites de ação do } \\
\text { profissional docente }\end{array}$ & $\begin{array}{l}\text { Docência apenas dos conteúdos profissionais, no âmbito das bases } \\
\text { tecnológicas do seu conhecimento }\end{array}$ \\
\hline Vantagens para os formandos & $\begin{array}{l}\text { Dois diplomas: um de graduação tecnológica e outro de licenciatura } \\
\text { Pode haver economia de carga horária graças ao currículo integrado (possível } \\
\text { economia máxima de carga horária pela integração: } 400 \text { horas) }\end{array}$ \\
\hline \multicolumn{2}{|c|}{ III. Curso de licenciatura para técnicos de nível médio ou equivalente } \\
\hline Carga horária mínima global & 2.400 horas \\
\hline Estrutura curricular pedagógica & $\begin{array}{l}800 \text { horas: parte técnica e de conhecimentos gerais da educação básica } \\
800 \text { horas de formação didático-pedagógica } \\
400 \text { horas de estágio pedagógico supervisionado } \\
400 \text { horas de estágio profissional específico }\end{array}$ \\
\hline Habilitados para docência em & Cursos técnicos de nível médio \\
\hline $\begin{array}{l}\text { Limites de ação do } \\
\text { profissional docente }\end{array}$ & $\begin{array}{l}\text { Docência apenas dos conteúdos profissionais, } \\
\text { no âmbito das bases tecnológicas do seu conhecimento }\end{array}$ \\
\hline Vantagens para os formandos & $\begin{array}{l}\text { Valorização de seus conhecimentos e de suas experiências } \\
\text { de curso técnico de nível médio }\end{array}$ \\
\hline
\end{tabular}




\section{Curso de licenciatura para concluintes do ensino médio}

\begin{tabular}{|l|l|}
\hline Carga horária mínima global & 3.200 horas \\
\hline & $\begin{array}{l}1.200 \text { horas de conteúdo técnico específico } \\
800 \text { horas de formação didático-pedagógica }\end{array}$ \\
\hline Estrutura curricular pedagógica & $\begin{array}{l}400 \text { horas de revisão de conhecimentos da educação básica } \\
400 \text { horas de estágio pedagógico supervisionado }\end{array}$ \\
\hline Habilitados para docência em & $\begin{array}{l}\text { Cursos técnicos de nível médio } \\
\text { (referente a ocupações não regulamentadas em lei) }\end{array}$ \\
\hline Limites de ação do & $\begin{array}{l}\text { Docência apenas dos conteúdos profissionais, no âmbito das bases } \\
\text { tecnológicas do seu conhecimento }\end{array}$ \\
\hline profissional docente & Incorporação da formação do técnico de nível médio \\
\hline Vantagens para os formandos & na modalidade subseqüente \\
\hline
\end{tabular}

\section{Questões gerais sobre organização curricular e pedagógica das licenciaturas para a educação profissional}

Como todo currículo escolar, o conjunto dos conteúdos da formação dos professores para a educação profissional, em quaisquer das modalidades de licenciatura acima expostas, não deve ser constituído simplesmente de uma agregação, mas ordenado, organizado e articulado segundo finalidades a serem alcançadas. Por isso, é importante realizar estudos e pesquisas sobre os conteúdos do processo de ensino-aprendizagem da tecnologia e sobre a organização desses conteúdos tomando-se em conta sua especificidade.

Alguns temas podem ser trabalhados transversalmente em todos os conteúdos previstos (os específicos do campo tecnológico, os da educação geral e os de fundamentação pedagógica), tais como: a evolução histórica da tecnologia; tecnologia e desenvolvimento científico; tecnologia, qualidade de vida e desenvolvimento humano; ética e tecnologia; tecnologia e mundos do trabalho; tecnologia e impacto socioambiental.

Os conteúdos específicos do campo tecnológico devem levar em conta as bases epistemológicas, sociológicas, políticas, psicológicas e didáticas próprias da área; reunir, num único movimento, sentidos unitários da tecnologia e os que recobrem sua diversidade; considerar os elementos de invariância da tecnologia para identificar e classificar as estruturas relativamente estáveis de organização curricular e dos processos de aquisição; contemplar a variação dos princípios da tecnologia, a heterogeneidade das abordagens, objetos e quadros conceituais; ser trabaIhados não de forma isolada, mas integrados a sistemas tecnológicos mais amplos, que incluem - mesmo os de menor porte ou alcance - conjuntos complexos de diversos e associados conhecimentos e dispositivos científicos, técnicos, jurídicos, políticos, econômicos, sociológicos e organizacionais.

Os conteúdos específicos do campo tecnológico correspondem a complexos tecnológicos que envolvem aspectos da realidade natural e social implicados na atividade humana do trabalho, transpostos para outro contexto de trabalho, o educacional, alicerçados em sólidas bases científicas e nas especificidades dos saberes profissionais.

A formação dos docentes da educação profissional demanda atenção cuidadosa aos conteúdos pedagógicos e educacionais relacionados à sociologia dos saberes tecnológicos e escolares, à psicologia das aprendizagens, ergonomia cognitiva, história da educação profissional e tecnológica, sociologia dos currículos da educação profissional, filosofia da educação, educa- 
ção tecnológica comparada, avaliação, construção da identidade docente profissional, métodos de ensino na educação profissional, organização escolar, políticas e gestão da educação profissional etc.

Portanto, é fundamental que conste da formação pedagógica dos docentes da educação profissional conteúdos sobre a educação brasileira, a história da educação profissional, as relações da educação profissional com o contexto econômico-social, os fundamentos da relação entre trabalho e educação, a discussão sobre produção de saberes no e sobre o trabalho, os espaços de articulação entre escola e trabalho, a influência das redes de pertencimento como legitimação e valorização dos sujeitos e seus saberes, mudanças no mundo do trabalho e suas implicações para a educação, políticas e legislação da educação profissional, objetivos e especificidades da educação profissional, conceitos e paradigmas sobre currículo na educação profissional, relações entre currículo, educação, cultura, tecnologia e sociedade; dualidade na organização curricular e currículo integrado; a construção curricular na educação profissional, didática e educação profissional, organização e planejamento da prática pedagógica na educação profissional, avaliação do processo de ensino-aprendizagem na educação profissional, docência na educação profissional etc.

Os núcleos contextual, estrutural e integrador, estabelecidos pela Resolução CNE no 2/97, podem se apresentar como uma possibilidade articuladora da estrutura curricular, com vistas a incentivar a integração de conhecimentos necessários à formação dos professores.

O núcleo contextual trata da "compreensão do processo ensino-aprendizagem referido à prática da escola, considerando tanto as relações que se passam no seu exterior, com seus participantes, quanto as suas relações, como instituições, como contexto imediato e o contexto em que está inserida"; contempla, assim, conhecimentos do papel da escola, da estrutura e legislação básica e tecnológica e dos fundamentos da educação básica e profissional.

O núcleo estrutural, "abordando conteúdos curriculares, sua organização seqüencial, a avaliação e integração com outras disciplinas, os métodos adequados ao desenvolvimento do conhecimento em pauta, bem como sua adequação ao processo ensino-aprendizagem", visa à compreensão do desenvolvimento do processo ensino-aprendizagem, dos conhecimentos específicos do campo tecnológico, da didática e da psicologia aplicadas à educação profissional.

O núcleo integrador, "centrado nos problemas concretos enfrentados pelos alunos na prática de ensino, com vistas ao planejamento e reorganização do trabalho escolar, discutidos a partir de diferentes perspectivas teóricas, por meio de projetos multidisciplinares, com a participação de professores das várias disciplinas do curso", visa uma ação reflexiva sobre a avaliação da aprendizagem, a metodologia e a prática de ensino profissional.

A formação didática dos professores da educação profissional se baseia na pesquisa da evolução histórica das soluções para problemas concretos; no acompanhamento da elaboração e da divulgação dos conhecimentos tecnológicos; em cenários que articulam diversas referências com relação aos objetos, produtos, tarefas, meios, materiais, documentos, organização e planificação de esquemas; em pesquisas específicas sobre ferramentas pedagógicas, uso da informática educativa, tratamento de textos, normas técnicas, vocabulário técnico, ambientes e materiais, saberes práticos e tácitos, transferência de tecnologia, julgamentos de valor, disciplinas e matrizes, currículo, relações com o saber, relações de saberes, atitudes e representações, práticas de ensino e de formação.

É importante considerar que os métodos de ensino-aprendizagem das tecnologias não são simples reflexos ou derivados do conhecimento tecnológico ou pedagógico, pois eles também fazem parte do conjunto das regras que conduzem às descobertas, invenções e resolução de problemas tecnológicos.

Na formação dos docentes para a educação profissional, é fundamental trabalhar diferentes formas de realização da transposição didática dos conteúdos específicos considerando a complexa diversidade apresentada por esta modalidade educacional e pelas dimensões econômicas, sociais e culturais das demandas dos contextos profissionais para os quais se formam os alunos.

Por isso se prevê proporcionar a maior proximidade possível do processo de ensino-aprendizagem com o contexto social e das relações do trabalho, garantindo uma ampla base científico-tecnológica e a articulação entre teoria e atividades práticas mediante a oferta de dois tempos de estágio, um na perspectiva do saber docente e outro na perspectiva do aprimoramento do saber técnico/tecnológico. 
LUCÍLIA REGINA DE SOUZA MACHADO

Socióloga, doutora em Educação, com pós-doutorado em Sociologia do Trabalho. É coordenadora do Mestrado Profissional em Gestão Social, Educação e Desenvolvimento Local do Centro Universitário UNA, em Belo horizonte.

\section{Referências}

ANDRÉ, M. Etnografia da prática escolar. Campinas, SP: Papirus, 1995.

CENTRAL ÚNICA DOS TRABALHADORES. Formação de formadores para educação profissional: a experiência da CUT; 1998/1999. São Paulo: CUT, 2000. 193 p.

CHARLOT, B. Da relação com o saber: elementos para uma teoria. Porto Alegre: Artes Médicas Sul, 2000.

CHUWER, Devoyra. A formação de educadores para a educação profissional. In: Tecnologia educacional. Rio de Janeiro, vol. 26, no 143 (out. /dez. 1998), p. 37-39.

DUBAR, C. A socialização: construção das identidades sociais e profissionais. Porto: Porto, 1997.

GRAMSCI, Antônio. Os intelectuais e a organização da cultura. Rio de Janeiro: Civilização Brasileira, 1978.

GRINSPUN, Mirian Paura Zippin. Educação tecnológica: desafios e perspectivas. São Paulo: Cortez, 1999.

HERRAIZ, Maria Luisa. Formación de formadores: manual didáctico. Montevideo: Cinterfor, 1994. 158 p.

NETO, Othílio Magela. A formação de professores para o ensino técnico no Brasil: um estudo histórico e documentário. (Dissertação de Mestrado). Mestrado em Educação Tecnológica, Cefet/MG, 1992. 227 p.

NÓVOA, A. (org). Os professores e a sua formação. Lisboa: D. Quixote, 1991. 